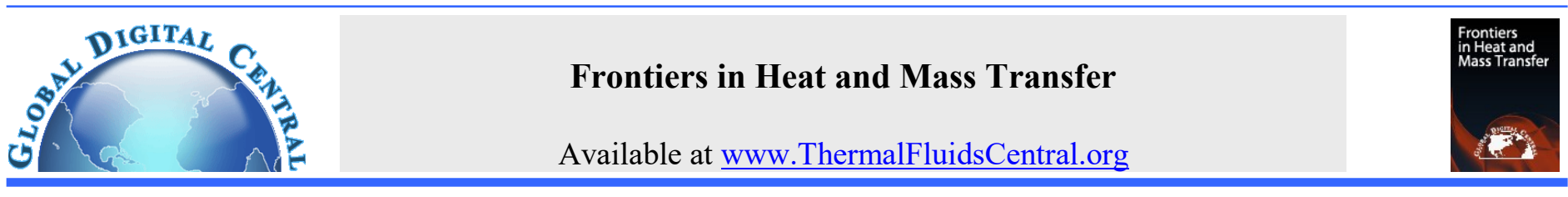

\title{
A SYSTEMATIC APPROACH FOR OPTIMAL POSITIONING OF HEATED SIDE WALLS IN A SIDE VENTED OPEN CAVITY UNDER NATURAL CONVECTION AND SURFACE RADIATION
}

\author{
Ravi Shankar Prasad ${ }^{\mathrm{a}}$, S.N. Singh ${ }^{\mathrm{b}}$, Amit Kumar Guptac,** \\ ${ }^{a}$ Heat Transfer Lab, Dept. of Mechanical Engg., Indian Institute of Technology (ISM), Dhanbad, Jharkhand, PIN 826004, India \\ ${ }^{b}$ Department of Mechanical Engineering, Indian Institute of Technology (ISM), Dhanbad, Jharkhand, PIN 826004, India \\ ${ }^{c}$ Department of Chemical Engineering, Birsa Institute of Technology Sindri, Dhanbad, Jharkhand, PIN 828123, India
}

\begin{abstract}
A systematic approach for the optimal positioning of multiple isothermal heat sources mounted on the walls of a side vented open cavity filled with natural air $(\mathrm{Pr}=0.70)$ under natural convection and surface radiation is discussed. A numerical investigation is performed for the different possible cases with the two isothermal heat sources of equal dimensions mounted on the walls of the cavity. The geometrical parameters like the aspect ratio $(\mathrm{A}=2)$, side vent ratio $(\mathrm{W} 1=0.50)$ and side port ratio $(\mathrm{W} 2=0.50)$ along with the most pertinent parameters like Rayleigh Number $\left(10^{4} \leqslant \mathrm{Ra} \leqslant 10^{7}\right)$ and the surface emissivity of walls $(0.05 \leqslant \varepsilon \leqslant 0.85)$ are the prime governing parameters in the different cases.
\end{abstract}

Keywords: Cooling, Open Boundary, Optimization, Stream Function, Thermal Management.

\section{INTRODUCTION}

In the last few years, our world has witnessed a phenomenal rapid growth in the electronic industry. The recent advancement in semiconductor, microprocessor and integrated circuit (IC) chip technology has a vital role behind this electronic revolution. Miniaturization of electronic circuits and compact design are the new features of modern electronic devices. This leads to a large volumetric heat generation and increased thermal stresses posing a big hindrance in the reliable performance of the electronic equipment. For a successful thermal design, the heat dissipation must be optimized in order to keep the temperature minimum and always well below the prescribed safe temperature limits. For heat dissipation and cooling, the natural convection is preferred due to its inherent simplicity, reliability, quite operation and economy. For the efficient heat dissipation, the positioning of the heat generating elements in cavities is one of the most important key factors affecting its cooling.

The motivation behind the present work is the rich and diverse literature of heat and mass transfer ranging over more than the last five decades. Abib and Jaluria (1988) made a numerical simulation of the buoyancy-induced flow in a partially open enclosure. Cahlon et al. (1991) developed a model for the convective cooling of electronic components with application to optimal placement. Angirasa and Mahajan (1993) studied the natural convection from the L-shaped corners with the adiabatic and cold isothermal horizontal walls. A significant contribution was made in the computational heat transfer by the several research papers based on coupled natural convection and surface radiation in different cavities. Balaji and Venkateshan (1994) studied the interaction of radiation with free convection in an open cavity. Balaji and Venkateshan (1995) analyzed the combined conduction, convection and radiation in a slot. Researchers contributed several research papers, which included the several new boundary conditions, which are widely acceptable now. Rao et al. (2000) studied the conjugate mixed convection with surface radiation from a vertical plate with the discrete heat source. Ramesh and Merzkirch (2001) made an experimental study of combined convective and radiative heat transfer in side-vented open cavities. Liu et al. (2002) proposed a method of coefficients identification in electronic system cooling simulation through the genetic algorithm. Rao et al. (2002) studied the effect of surface radiation on conjugate mixed convection in a vertical channel with a discrete heat source in each wall. Singh and Venkateshan (2004) made a numerical study of natural convection with surface radiation in side-vented open cavities. After these preliminary research works in computational heat transfer, the researchers worked for the optimization of cooling of heat sources inside the cavity with the view of electronic cooling and the other practical applications. Tseng et al. (2007) developed an optimal parametric design to improve chip cooling. Cheng et al. (2008) made a numerical simulation of conjugate heat transfer in electronic cooling and analysis based on field synergy principle. Felczak et al. (2009) suggested a method for optimal placement of electronic devices in forced convective cooling conditions. Sudhakar et al. (2010) proposed a heuristic approach to optimal arrangement of multiple heat sources under conjugate natural convection. Tigner et al. (2013) analyzed a platform for thermal management studies of microelectronics cooling methods. Cuce and Cuce (2014) optimized the configurations to enhance heat transfer from a longitudinal fin exposed to natural convection and radiation. Gong et al. (2015) made a numerical study on layout of micro-channel heat sink for thermal management of electronic devices. Hotta and Venkateshan (2015) developed a technique for the optimal distribution of discrete heat sources under natural convection based on artificial neural network (ANN) and genetic algorithm (GA). Singh and Singh (2015) studied conjugate free convection with surface radiation in open top cavity.

\footnotetext{
* Corresponding author.Email: akguptachem@gmail.com
} 
Alexandersen et al. (2016) performed large scale three-dimensional topology optimization of heat sinks cooled by natural convection. Baudoin et al. (2017) optimized the distribution of a large number of power electronics components cooled by conjugate turbulent natural convection. Hati et al. (2017) made an optimal natural convection heat transfer improvement by combining periodic heating temperature, cavity inclination and nanofluid. Joo et al. (2017) studied the topology optimization of heat sinks in natural convection considering the effect of shape dependent heat transfer coefficient. Lampio and Karvinen (2017) studied the optimization of convectively cooled heat sinks. Saglietti et al. (2017) studied the adjoint optimization of natural convection problems in a differentially heated cavity. Karatas and Derbentli (2018) studied natural convection and radiation in rectangular cavities with one active vertical wall. Kwon et al. (2018) presented an analytic approach to thermal optimization of horizontally oriented radial plate-fin heat sinks in natural convection. Lugarini et al. (2018) studied natural convection and surface radiation in a heated wall with the $\mathrm{C}$-shaped fracture. The above research works show the importance of natural convection and surface radiation heat transfer in the practical applications like the electronic cooling.

Natural convection and surface radiation has been studied in the open and closed cavities having different geometries. This includes the detailed numerical and experimental studies with several different approaches. In the recent times, the efficient thermal management of the heat generating devices is one of the prime concern. A number of research works are being carried out for the optimal placement of heat sources, fins and heat sinks.

Tseng et al. (2007), Felczak et al. (2009) and Baudoin et al. (2017) contributed to the optimization of the cooling of the electronic components. A heuristic approach was proposed by Sudhakar et al. (2010) for the optimal arrangement of multiple heat sources under conjugate natural convection. Hotta and Venkateshan (2015) developed a technique based on artificial neural network (ANN) and genetic algorithm (GA) for the optimal distribution of discrete heat sources under natural convection. Several other algorithms and techniques were proposed by the different researchers for an efficient thermal management in the cavity. Cuce et al. (2014) and Kwon et al. (2018) optimized the cooling of fins exposed to convective cooling. Joo et al. (2017) proposed the topology optimization of the heat sinks under natural convection. Saglietti et al. (2017) performed adjoint optimization of the natural convection problems in the differentially heated cavity. Tigner et al. (2013) and Gong et al. (2015) studied the thermal management of the electronic devices.

In the design of packaging of an electronic gadget, devices etc. the prediction and control of its temperature within the housing is always the prime interest. It is always intended to minimize the thermal interaction between the different heat sources to reduce the temperature inside the electronic packaging within the permissible safe limits. A major reason of the failure of integrated circuits (IC) is the poor dissipation of heat produced by it. The optimal placement of heat generating components like integrated circuits etc. inside the housing of electronic devices is a major challenge. Different approaches and techniques are proposed for the optimal placement of heat sources inside the cavity.

There are several approaches, techniques and algorithms for the optimal placement of heat sources inside the cavity. But these algorithms or techniques must be physically applicable in a practical situation with the all other constraints. Sometimes the simple and direct application of basic thumb rules may be the best approach suited to a practical situation. This may result to an iterative thermal design problem, but the simplicity of the solution makes it widely acceptable.

This paper presents a systematic approach for the optimal placement of heat sources. A systematic approach is a procedure based on the application of past experience consisting of clearly defined and repeatable steps and an evaluation of the different possible outcomes. The prime goal of a systematic approach is to identify the most efficient solutions suitable for a practical situation eliminating the other inefficient solutions to generate the optimum results consistently.
In the present problem, all the possible configurations of heat sources are discussed. Then the cooling of heat sources in the different configurations is compared to find the few (two in the present case) possible configurations for the optimal placement of heat sources in the cavity for the maximum cooling of heat sources. Then these few cases are discussed in greater detail to find out the best one configuration of heat sources for the optimum cooling. Thus, the optimal configuration having the maximum cooling of heat sources is achieved.

Numerical investigation of coupled laminar natural convection and surface radiation is one of the important basic tools for the theoretical analysis of cooling within a cavity. Multiple heat sources mounted on the side walls of a cavity is one of the practical situation most frequently encountered. An open cavity is filled with natural air $(\mathrm{Pr}=0.70)$ as the fluid medium. Numerical investigation may be performed for a number of different cases. For a rational comparison between the similar cases and developing a systematic approach for the positioning of heat sources, there only two isothermal heat sources mounted on the walls of right side top vented open cavity is considered. But the results obtained in this case may be extended to the other types of open cavities with the multiple heat sources. The results obtained are summarized and generalized within the reasonable range and scope of the problem. This may be applied for the optimal placement of the heat sources in the other geometries of the open or closed cavity. The number of heat sources also may be two or greater. The conclusions derived here are widely applicable in such problems.

\section{MATHEMATICAL FORMULATION}

\subsection{Problem Geometry}

A right side top vented, top open cavity having height ' $\mathrm{H}$ ', horizontal width 'd' $(=\mathrm{H} / 2)$, right side bottom vent wall height ' $w 1(=\mathrm{H} / 2)$ ' and right side top port height ' $\mathrm{w} 2(=\mathrm{H} / 2)$ ' is considered as shown in Fig. 1. From the geometry of the cavity, $\mathrm{H}=\mathrm{w} 1+\mathrm{w} 2$. Here, the Cartesian coordinate system is used as shown in Fig. 1.

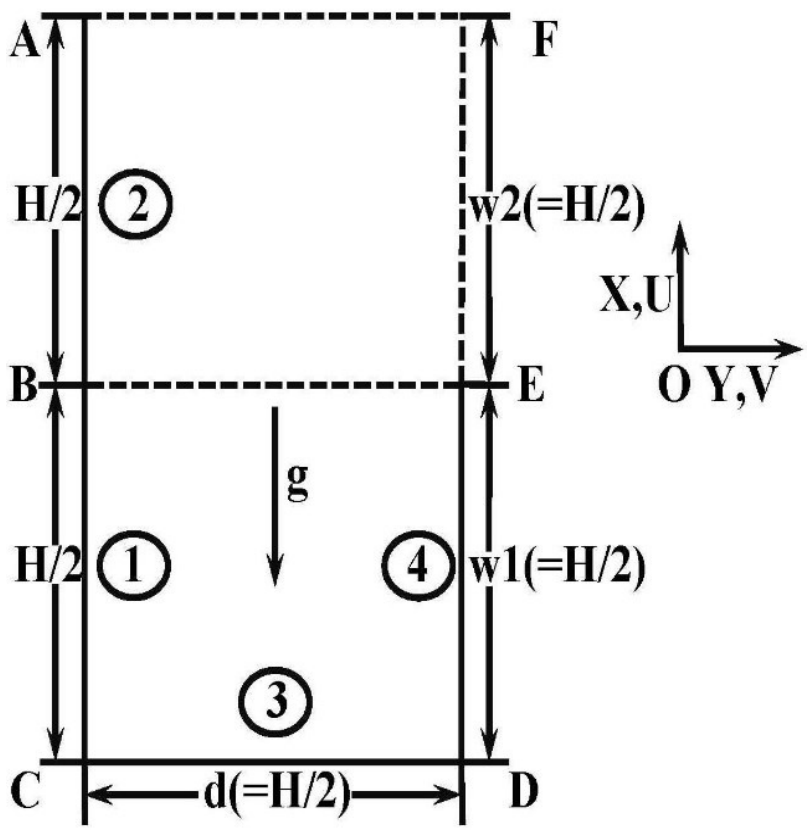

Fig. 1 Schematic diagram of problem geometry showing the computational domain.

In this figure, there are four locations marked 1, 2, 3 and 4 within the cavity for placing the isothermal heat sources. There are two locations at the left, one at the bottom and one at the right. The dimension of each location is equal to $\mathrm{H} / 2$. There are two isothermal heat sources, each having dimension $\mathrm{H} / 2$ to be placed at any two of these four locations 
within the cavity and the walls at the remaining other two locations are considered adiabatic. Thus, there are total ${ }^{4} \mathrm{C}_{2}=\frac{4 !}{2 !(4-2) !}=6$ ways of placing the two isothermal heat sources and the two adiabatic walls as tabulated below in Table 1 .

Table 1 Location of heat sources and adiabatic walls in different cases.

\begin{tabular}{|l|l|l|l|l|l|l|}
\hline Case No. & 1 & 2 & 3 & 4 & 5 & 6 \\
\hline $\begin{array}{l}\text { Location of isothermal } \\
\text { heat sources }\end{array}$ & 1,2 & 1,3 & 1,4 & 2,3 & 2,4 & 3,4 \\
\hline $\begin{array}{l}\text { Location of adiabatic } \\
\text { walls }\end{array}$ & 3,4 & 2,4 & 2,3 & 1,4 & 1,3 & 1,2 \\
\hline
\end{tabular}

There in each of the above six cases, the total area of isothermal surfaces and the total area of adiabatic surfaces remains constant. In each of these six cases, the total surface area of the isothermal surface and the total area of adiabatic surface each equals to the $50 \%$ of the total inner surface area of the cavity.

\subsection{Formulation for Natural Convection}

The two dimensional steady incompressible laminar natural convection heat transfer in the right side top vented, top open cavity is considered using the Cartesian coordinate system as shown in Fig. 1. The governing equations in stream function $(\psi)$ - vorticity $(\omega)$ form, for a constant property fluid under the Boussinesq approximation, in the non-dimensional form are:

$U \frac{\partial \omega}{\partial X}+V \frac{\partial \omega}{\partial Y}=\operatorname{Pr} .\left[\frac{\partial^{2} \omega}{\partial X^{2}}+\frac{\partial^{2} \omega}{\partial Y^{2}}\right]-\operatorname{Ra} \frac{\partial \theta}{\partial Y}$

$\frac{\partial^{2} \psi}{\partial X^{2}}+\frac{\partial^{2} \psi}{\partial Y^{2}}=-\operatorname{Pr} . \omega$

$U \frac{\partial \theta}{\partial X}+V \frac{\partial \theta}{\partial Y}=\frac{\partial^{2} \theta}{\partial X^{2}}+\frac{\partial^{2} \theta}{\partial Y^{2}}$

where $U=\frac{\partial \psi}{\partial Y}, V=-\frac{\partial \psi}{\partial X} \quad$ and $\quad \omega=\frac{\partial V}{\partial X}-\frac{\partial U}{\partial Y}$

\subsection{Formulation for Surface Radiation}

The radiosity-irradiation formulation is used to describe the surface radiation based on Balaji and Venkateshan (1994, 1995), Rao et al. (2000, 2002) and Singh and Venkateshan (2004). The walls are assumed to be diffuse and gray i.e. independent of direction and wavelength. For an elemental area on the boundary of the cavity, the non-dimensional radiosity is given by the following equation.

$J_{i}=\varepsilon_{i}\left(T_{i} / T_{h}\right)^{4}+\left(1-\varepsilon_{i}\right) \sum_{j=1}^{2(m+n-2)} F_{i j} J_{j}$

where $i=1,2(m+n-2)$

Here the view factors $\mathrm{F}_{\mathrm{ij}}$ are calculated by using the Hottel's crossed string method.

\subsection{Boundary Conditions}

The prime interest of the present study is to find the flow and temperature field in the domain or area enclosed by the cavity. For this computational domain enclosed by the cavity, the boundary conditions can be easily specified. The boundary conditions for the computational domain in terms of non-dimensional stream function, vorticity and temperature are based on the Balaji and Venkateshan (1994, 1995), Rao et al. (2000, 2002) and Singh and Venkateshan (2004). The boundary conditions are specified in terms of the velocities $\mathrm{U}$ and $\mathrm{V}$ also for the clarity and simplicity only.

\section{Boundary conditions for the adiabatic walls}

At the adiabatic walls, the convection and radiation energy transfer balance each other.

For the case of left adiabatic wall: $\quad-\frac{\partial \theta}{\partial Y}=\mathrm{N}_{\mathrm{rc}}(J-G)$

(Used in cases 2, 3, 4, 5 and 6)

For the case of bottom adiabatic wall: $-\frac{\partial \theta}{\partial X}=\mathrm{N}_{\mathrm{rc}}(J-G)$

(Used in cases 1, 3 and 5)

For the case of right bottom adiabatic vent wall: $\frac{\partial \theta}{\partial Y}=\mathrm{N}_{\mathrm{rc}}(J-G)$

(Used in cases 1,2 and 4)

\section{Boundary Conditions for the right top open boundary EF}

$Y=1, W 1<X<A, \omega=0, \frac{\partial U}{\partial X}=-\frac{\partial V}{\partial Y}=\frac{\partial^{2} \psi}{\partial X \partial Y}=0$

Here in this case neither the vertical velocity $(U)$ nor the horizontal velocity $(\mathrm{V})$ is assumed to be zero. This is a mixed boundary condition providing the smooth variation of the two velocity components. By the definition of stream function, the equation of continuity is satisfied everywhere. But this smoothness boundary condition makes the continuity equation satisfied everywhere as well as makes both of the derivative terms identically zero along the opening in the right wall.

Rao et al. (2000) have implemented this boundary condition in studying the problem of laminar mixed convection from heated vertical plate and found this boundary condition the most appropriate. Singh and Venkateshan (2004) compared this boundary condition with the other possible boundary conditions for studying the natural convection and surface radiation in side vented open cavities and found it to be the most appropriate.

\section{Boundary Conditions for the top open boundary AF}

According to the Balaji and Venkateshan (1994, 1995), Rao et al. (2000, 2002) and Singh and Venkateshan (2004), the boundary condition in such a case is proposed as:

$$
\begin{aligned}
& X=A, \quad 0<Y<1, \quad \frac{\partial \omega}{\partial X}=0, \quad V=-\frac{\partial \psi}{\partial X}=0, \\
& \text { If } U=\frac{\partial \psi}{\partial Y}>0, \frac{\partial \theta}{\partial X}=0, \quad \text { or }, U=\frac{\partial \psi}{\partial Y}<0, \theta=0
\end{aligned}
$$

The boundary conditions for the top opening AF and the right side opening EF in all the six cases considered are same.

\section{Boundary Conditions for the solid walls from the Case I to VI}

The stream function, vorticity and temperature boundary conditions specified on each of the solid boundary are based on the several research papers by Balaji and Venkateshan $(1994,1995)$, Rao et al. $(2000,2002)$ and Singh and Venkateshan (2004). The boundary conditions are written here in terms of the velocities $\mathrm{U}$ and $\mathrm{V}$ also for the clarity and simplicity only.

\section{Case I 1, 2 Isothermal heat sources; 3, 4 Adiabatic walls}

(1) For left bottom isothermal wall:

$$
\begin{array}{ll}
0<X<A / 2, & Y=0, \quad U=0, V=0 \text { or } \psi=0, \\
\omega=-\frac{1}{\operatorname{Pr}} \frac{\partial^{2} \psi}{\partial Y^{2}}, & \theta=1
\end{array}
$$

(2) For left top isothermal wall:

$$
A / 2<X<A, \quad Y=0, \quad U=0, V=0 \text { or } \psi=0,
$$


$\omega=-\frac{1}{\operatorname{Pr}} \frac{\partial^{2} \psi}{\partial Y^{2}}, \quad \theta=1$

(3) For bottom adiabatic wall:

$$
\begin{array}{ll}
X=0, & 0<Y<1, \quad U=0, V=0 \text { or } \psi=0, \\
\omega=-\frac{1}{P r} \frac{\partial^{2} \psi}{\partial X^{2}}, & -\frac{\partial \theta}{\partial X}=\mathrm{N}_{\mathrm{rc}}(J-G)
\end{array}
$$

(4) For right bottom adiabatic vent wall:

$$
\begin{array}{lll}
0<X<W 1, & Y=1, & U=0, V=0 \text { or } \psi=0, \\
\omega=-\frac{1}{P r} \frac{\partial^{2} \psi}{\partial Y^{2}}, & \frac{\partial \theta}{\partial Y}=\mathrm{N}_{\mathrm{rc}}(J-G) &
\end{array}
$$

Similarly the boundary conditions for the other five cases also may be written.

\section{METHOD OF SOLUTION}

The governing Eqs. (1), (2) and (3) are transformed into finite difference equations using the finite volume based finite difference method. Then the Gauss-Seidel iterative procedure is used to solve the algebraic equations obtained. The set of discretized equations obtained are solved by using a line-by-line procedure of the tri-diagonal matrix algorithm (TDMA) or Thomas algorithm. A computer code for a FORTRAN platform is developed for solving the discretized equations. An optimum grid size of 51x61 is selected for the computational domain on the basis of grid sensitivity analysis presented later (as suggested by Singh and Venkateshan, 2004). A semi-cosine and a cosine function have been chosen to generate the grids along $\mathrm{X}$ and $\mathrm{Y}$ directions respectively in the computational domain of the cavity. These semi-cosine and cosine grids are very fine near the solid boundaries, where the gradients are very steep, while they are relatively coarser in the remaining part of the domain as shown in Fig. 2. Derivative boundary conditions are implemented by three points formulae using the Lagrangian polynomial. The integration required in calculations is performed by using the Simpson's one-third rule for the non-uniform step size. Upwinding has been used for representing the advection terms to ensure the stable and convergent solutions. Under relaxation with a relaxation parameter 0.1 is used for all the equations except for the radiosity equations, where the relaxation parameter 0.5 is used. A convergence criterion $(\delta)$ in the percentage form has been defined as

$\delta=\left|\left(\zeta_{\text {new }}-\zeta_{\text {old }}\right) / \zeta_{\text {new }}\right| X 100$,

where $\zeta$ is any dependent variable like $\psi, \omega, \theta, \mathrm{J}$ and $\mathrm{G}$, over which the convergence test is applied. Here the subscripts "old" and "new" refers to the first and second values of $\zeta$ calculated in the any two successive iterations. A convergence criterion of $0.1 \%$ or $10^{-3}$ has been used for stream function, vorticity and temperature, whereas the convergence criterion of $0.01 \%$ or $10^{-4}$ has been used for the radiosity.

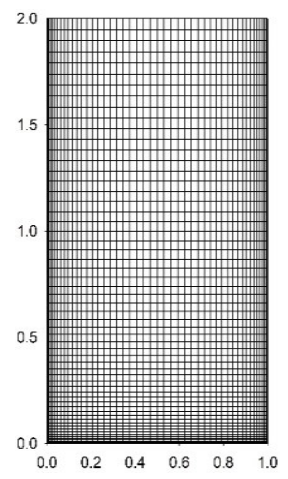

Fig. 2 Typical grid pattern used in the analysis. Grid size $=51 \times 61$. $(\mathrm{A}=2, \mathrm{~W} 1=\mathrm{W} 2=0.50)$

\section{RESULTS AND DISCUSSION}

The Table 2 shows the range of parameters considered in the present study. The results are presented with the objective of analytical comparison between the different cases considered. A grid sensitivity study is presented for the determination of optimum grid size for the present study.

Table 2 Range of parameters considered for the present study.

\begin{tabular}{|l|l|}
\hline Parameters & Range \\
\hline Rayleigh Number, $\mathrm{Ra}_{\mathrm{H}}$ & $10^{4}-10^{7}$ \\
\hline Conduction-radiation parameter, $\mathrm{N}_{\mathrm{rc}}$ & 22.6253 \\
\hline Emissivity, $\varepsilon$ & $0.05-0.85$ \\
\hline Temperature ratio, $\mathrm{T}_{\mathrm{R}}$ & 0.872 \\
\hline Aspect Ratio, $\mathrm{A}$ & 2 \\
\hline Vent Ratio, W1 & 0.50 \\
\hline Port Ratio, W2 & 0.50 \\
\hline
\end{tabular}

\subsection{Grid Sensitivity Study}

A grid sensitivity study or grid independence study is performed to find the optimum grid size as suggested by Singh and Venkateshan (2004). In the each case of present problem, there is an interaction between natural convection and surface radiation. The grid sizes affect the convection and radiation Nusselt numbers differently. Hence in order to determine the optimum grid size, the effect of increasing the grid size on both of the convection Nusselt Number and the radiation Nusselt number must be analyzed. Here the grid sensitivity analysis is done into two parts. In the first part ' $n$ ' is fixed and in the second part ' $m$ ' is fixed at a moderate value of 31 , where $m$ and $n$ are the total number of grid points in the horizontal $\mathrm{Y}$ direction and the vertical $\mathrm{X}$ direction respectively.

Table 3 Grid independence study $\mathrm{n}=31$, $\mathrm{m}$ varied (For case $\mathrm{I}, \mathrm{A}=2$, $\mathrm{N}_{\mathrm{rc}}=22.6253, \mathrm{Pr}=0.70, \mathrm{RaH}=1.075 \times 10^{6}, \mathrm{~T}_{\mathrm{R}}=0.872$, $\mathrm{W} 1=\mathrm{W} 2=0.50, \varepsilon=0.85)$.

\begin{tabular}{|l|l|l|l|l|l|l|}
\hline$m \times n$ & $\overline{N u}_{C}$ & $\overline{N u}_{R}$ & $\overline{N u}_{T}$ & $\begin{array}{l}\% \\
\text { Change } \\
\text { in } \overline{N u}_{C}\end{array}$ & $\begin{array}{l}\% \\
\text { Change } \\
\text { in } \overline{N u}_{R}\end{array}$ & $\begin{array}{l}\% \\
\text { Change } \\
\text { in } \overline{N u}_{T}\end{array}$ \\
\hline $21 \times 31$ & 16.00 & 13.94 & 29.94 & --- & --- & --- \\
\hline $31 \times 31$ & 14.89 & 13.75 & 28.64 & 6.94 & 1.36 & 4.34 \\
\hline $41 \times 31$ & 13.99 & 14.17 & 28.16 & 6.04 & 3.05 & 1.68 \\
\hline $51 \times 31$ & 13.85 & 14.17 & 28.02 & 1.00 & 0 & 0.50 \\
\hline $61 \times 31$ & 13.73 & 14.16 & 27.89 & 0.87 & 0.07 & 0.46 \\
\hline $71 \times 31$ & 13.66 & 14.17 & 27.83 & 0.51 & 0.07 & 0.22 \\
\hline $81 \times 31$ & 13.62 & 14.17 & 27.79 & 0.29 & 0 & 0.14 \\
\hline $91 \times 31$ & 13.57 & 14.17 & 27.74 & 0.37 & 0 & 0.18 \\
\hline
\end{tabular}

Table 4 Grid independence study $\mathrm{m}=31$, $\mathrm{n}$ varied (For case $\mathrm{I}, \mathrm{A}=2$, $\mathrm{N}_{\mathrm{rc}}=22.6253, \mathrm{Pr}=0.70, \mathrm{Ra}_{\mathrm{H}}=1.075 \times 10^{6}, \mathrm{~T}_{\mathrm{R}}=0.872$, $\mathrm{W} 1=\mathrm{W} 2=0.50, \varepsilon=0.85)$.

\begin{tabular}{|l|l|l|l|l|l|l|}
\hline$m \times n$ & $\overline{N u}_{C}$ & $\overline{N u}_{R}$ & $\overline{N u}_{T}$ & $\begin{array}{l}\% \\
\text { Change } \\
\text { in } \overline{N u}_{C}\end{array}$ & $\begin{array}{l}\% \\
\text { Change } \\
\text { in } \overline{N u}_{R}\end{array}$ & $\begin{array}{l}\% \\
\text { Change } \\
\text { in } \overline{N u}_{T}\end{array}$ \\
\hline $31 \times 21$ & 12.35 & 13.76 & 26.11 & --- & --- & --- \\
\hline $31 \times 31$ & 14.89 & 13.75 & 28.64 & 20.57 & 0.07 & 9.69 \\
\hline $31 \times 41$ & 14.39 & 13.99 & 28.38 & 3.36 & 1.74 & 0.91 \\
\hline $31 \times 51$ & 14.35 & 14.00 & 28.35 & 0.28 & 0.07 & 0.11 \\
\hline $31 \times 61$ & 14.32 & 13.92 & 28.24 & 0.21 & 0.57 & 0.39 \\
\hline $31 \times 71$ & 14.85 & 13.71 & 28.56 & 3.70 & 1.51 & 1.13 \\
\hline $31 \times 81$ & 14.32 & 13.88 & 28.20 & 3.57 & 1.24 & 1.26 \\
\hline $31 \times 91$ & 14.84 & 13.71 & 28.55 & 3.63 & 1.22 & 1.24 \\
\hline
\end{tabular}


Here in the Table 3, it is observed that the change in $\overline{\mathrm{Nu}}_{\mathrm{C}}$ and $\overline{\mathrm{Nu}}_{\mathrm{T}}$ is less that than $1 \%$ and value of $\overline{\mathrm{Nu}}_{\mathrm{R}}$ remains almost constant for the grid size $51 \times 31$ and above. Therefore, $\mathrm{m}=51$ is selected.

In the Table 4, the change in $\overline{\mathrm{Nu}}_{\mathrm{C}}$ is minimum for grid size $31 \times 61$, whereas the change in $\overline{\mathrm{Nu}}_{\mathrm{T}}$ is minimum for the grid size $31 \times 51$. Change in $\overline{\mathrm{Nu}}_{\mathrm{R}}$ is minimum for grid size $31 \times 31$, which is a relatively coarse grid. At grid size $31 \times 61$, the change in $\overline{\mathrm{Nu}}_{\mathrm{R}}$ has the second lowest value. On close observation of the values of $\overline{\mathrm{Nu}}_{C}$ and $\overline{\mathrm{Nu}}_{\mathrm{R}}$ in Table 4, it is found that $\overline{\mathrm{Nu}}_{\mathrm{C}}$ oscillates with the increase in the grid size by increasing $\mathrm{n}$ and converges in a small zone of confusion at the grid size $31 \times 61$ and above. The $\overline{\mathrm{Nu}}_{\mathrm{R}}$ converges at the lower grid size in comparison with $\overline{\mathrm{Nu}}_{\mathrm{C}}$. The error becomes smaller on increasing the grid size and it is slower for $\overline{\mathrm{Nu}}_{\mathrm{C}}$.

For the grid size $31 \times 61$ and higher, the value of $\overline{\mathrm{Nu}}_{\mathrm{C}}$ oscillates in a narrow range of 14.32 to 14.85 . Similarly for the grid size $31 \times 61$ and higher, the value of $\overline{\mathrm{Nu}_{\mathrm{R}}}$ oscillates in a narrow range of 13.71 to 13.92 .

By selecting $\mathrm{n}=61$, the error in $\overline{\mathrm{Nu}_{\mathrm{C}}}$ with respect to its mean value is less than $2 \%$. Similarly by selecting $\mathrm{n}=61$, the error in $\overline{\mathrm{Nu}_{R}}$ with respect to its mean value is less than $1 \%$. The change in various parameters like the bottom wall temperature and the vertical air velocity at the different horizontal sections is not significant with the further increase in the grid size by increasing $n$. Thus, $n=61$ may be selected without affecting the results significantly. Hence, $n=61$ is selected.

Therefore, on careful observation of both the Tables 3 and 4, it is found that the grid size $51 \times 61$ is optimum for the present problem. Any further increase in the grid size increases the computational work manifolds without more significant improvement in the accuracy of results.

\subsection{Validation}

For validation, the results obtained for the case I is compared with the results of the experimental work by Ramesh and Merzkirch (2001). Ramesh and Merzkirch (2001) have presented the results of their experimental study for a very narrow range of Rayleigh numbers $10^{5}-10^{6}$ and for $\mathrm{A}=2, \mathrm{~W} 1=\mathrm{W} 2=0.50$ and $\varepsilon=0.05$ and 0.85 (Later referred as low emissivity and high emissivity respectively). A typical case considered in their study corresponds to the following set of parameters i.e. $\mathrm{H}=0.07 \mathrm{~m}, \mathrm{~d}=0.035 \mathrm{~m}, \mathrm{~T}_{\infty}=293 \mathrm{~K}, \mathrm{~T}_{\mathrm{h}}=\mathrm{T}_{\infty}+\Delta \mathrm{T}=293 \mathrm{~K}+43 \mathrm{~K}$ $=336 \mathrm{~K}, \varepsilon=0.05$ and 0.85 .

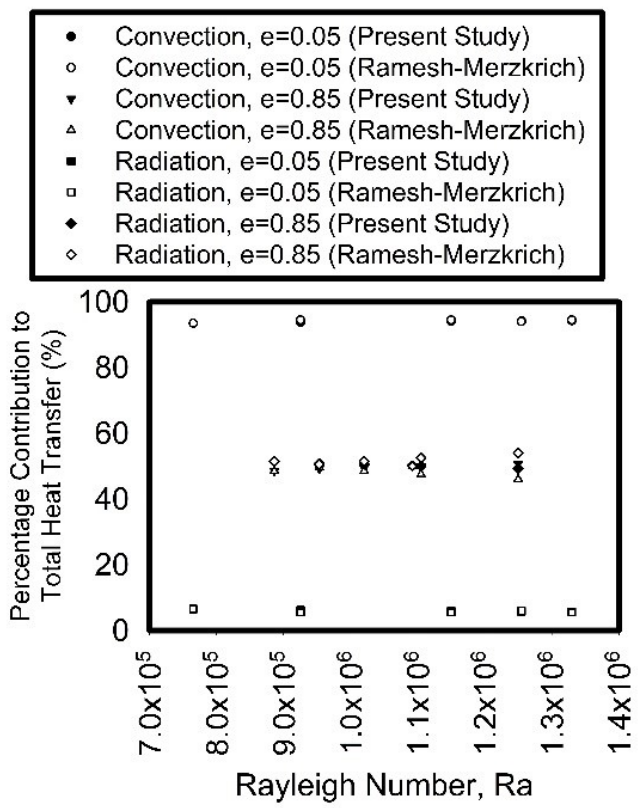

Fig. 3 Effect of emissivity on the percentage of heat transferred by natural convection and surface radiation.
The total Nusselt number corresponding to the low emissivity case for the present study and Ramesh-Merzkirch study are 15.12 and 17 respectively. The total Nusselt number corresponding to the high emissivity case for the present study and Ramesh-Merzkirch study are 27.57 and 28.7 respectively. These values show a good agreement between the present study and the referred experimental work.

Present problem involves the interaction between natural convection and surface radiation. Percentage of heat transferred by natural convection and surface radiation is an important parameter compared between the present work and the experimental work of Ramesh-Merzkirch at the different Rayleigh Numbers. There is an excellent agreement between the present numerical results and referred experimental work for the different Rayleigh number and emissivity as shown in Fig. 3.

\subsection{The Streamlines for the different cases}

The streamlines for the all six cases at $\mathrm{A}=2, \mathrm{~N}_{\mathrm{rc}}=22.6253, \operatorname{Pr}=0.70$, $\mathrm{RaH}=1.075 \times 10^{6}, \mathrm{~T}_{\mathrm{R}}=0.872, \mathrm{~W} 1=\mathrm{W} 2=0.50, \varepsilon=0.85$ is shown in Fig. 4.

From the streamlines in case I, II and III, it is observed that the air streams are entering in the open cavity from the right side port and top opening and leaving through the top opening as shown in Fig. 4. In the cases IV, V and VI, the circulation loops are prominently observed, which causes the weak cooling inside the cavity. In the case VI, due to the influence of heated right side wall and bottom wall the streamlines are very dense showing the very high amount of hot air circulation.
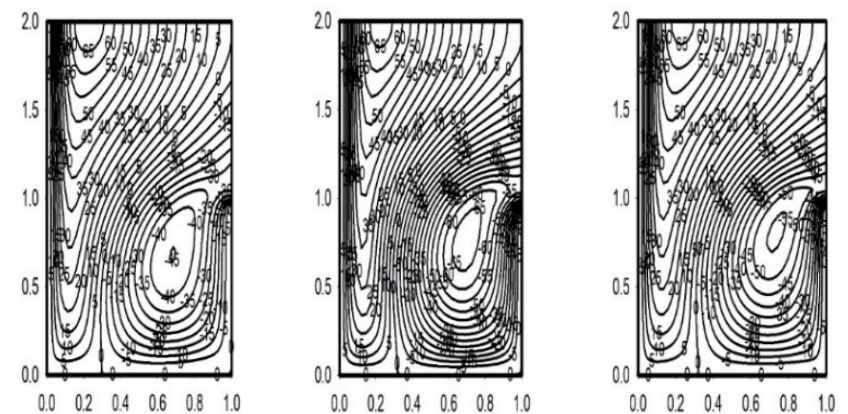

Case I

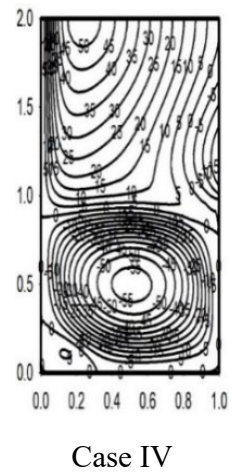

Case II

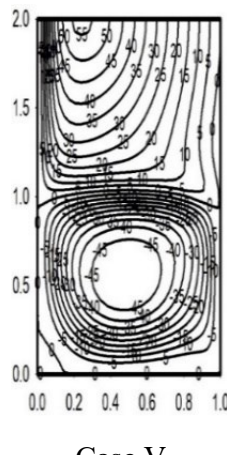

Case V
Case III

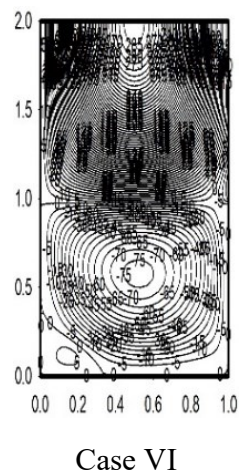

Fig. 4 Streamlines for the six cases $\left(A=2, N_{r c}=22.6253, \operatorname{Pr}=0.70\right.$, $\left.\mathrm{RaH}_{\mathrm{H}}=1.075 \times 10^{6}, \mathrm{~T}_{\mathrm{R}}=0.872, \mathrm{~W} 1=\mathrm{W} 2=0.50, \varepsilon=0.85\right)$.

\subsection{The Isotherms for the different cases}

The isotherms for the all six cases at $\mathrm{A}=2, \mathrm{~N}_{\mathrm{rc}}=22.6253, \operatorname{Pr}=0.70$, $\mathrm{RaH}_{\mathrm{H}}=1.075 \times 10^{6}, \mathrm{~T}_{\mathrm{R}}=0.872, \mathrm{~W} 1=\mathrm{W} 2=0.50, \varepsilon=0.85$ is shown in Fig. 5.

From the isotherms of case I, II and III, it is observed that the temperature of the bulk of cavity is very close to the ambient temperature. But in the cases IV, V and VI, the temperature of the lower half of the cavity is very high due to circulation of hot air as shown in Fig. 5. 

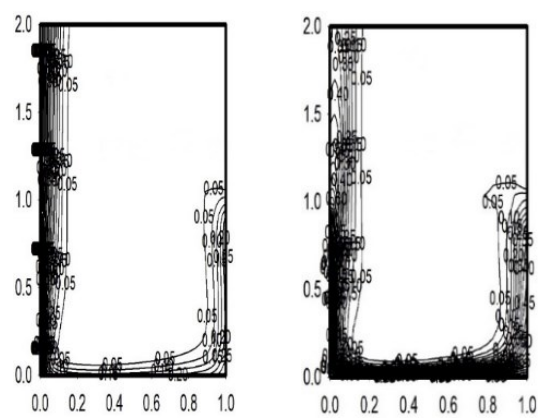

Case I

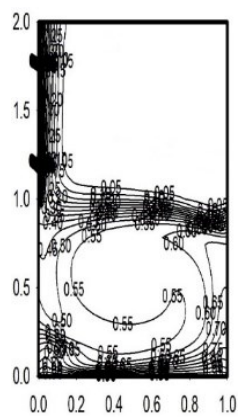

Case IV

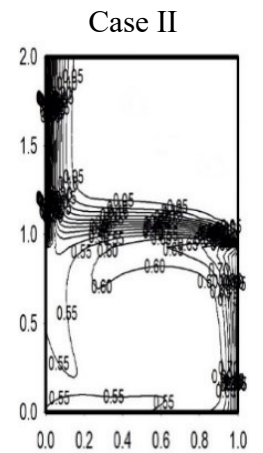

Case V
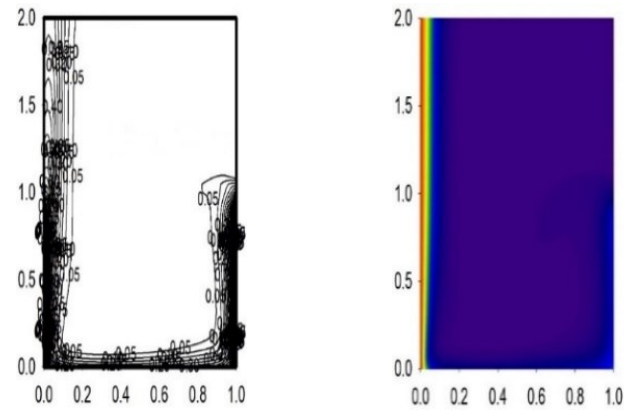

Case I

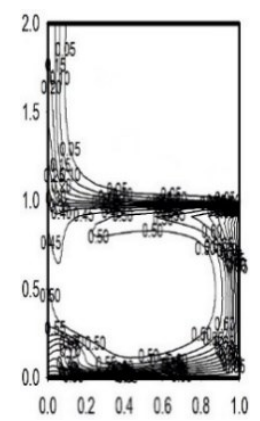

Case VI

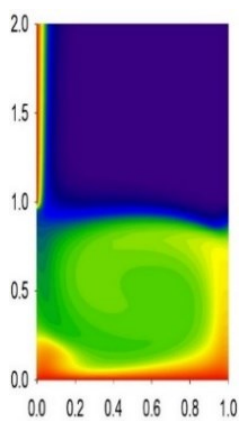

Case IV

Fig. 5 Isotherms for the six cases $\left(\mathrm{A}=2, \mathrm{~N}_{\mathrm{rc}}=22.6253, \mathrm{Pr}=0.70\right.$, $\left.\mathrm{RaH}=1.075 \times 10^{6}, \mathrm{~T}_{\mathrm{R}}=0.872, \mathrm{~W} 1=\mathrm{W} 2=0.50, \varepsilon=0.85\right)$.

\subsection{The Isotherm Color Contours for the different cases}

The isotherms colored contours for the all six cases at $\mathrm{A}=2$, $\mathrm{N}_{\mathrm{rc}}=22.6253, \operatorname{Pr}=0.70, \mathrm{RaH}=1.075 \times 10^{6}, \mathrm{~T}_{\mathrm{R}}=0.872$, $\mathrm{W} 1=\mathrm{W} 2=0.50, \varepsilon=0.85$ is shown in Fig. 6 .

From the color contour isotherms of case I, II and III, it is observed that the temperature of the bulk of cavity is very close to the ambient temperature. But in the cases IV, V and VI, the temperature of the lower half of the cavity is very high due to circulation of hot air as shown in Fig. 6.

The streamlines and isotherm contours for the six cases are compared and used for discussion in the next sections.

\subsection{Shape factor of one heat source with respect to another heat source}

Shape factor of one heat source with respect to another heat source is one of the key factors affecting the cooling of one heat source by natural convection and surface radiation in the presence of another heat source.

According to the reciprocity relationship for the two isothermal heat sources, $A_{1} \cdot F_{12}=A_{2} \cdot F_{21}$. Here $A_{1}=A_{2}$, hence $F_{12}=F_{21}$. Hence the shape factor of first heat source with respect to second heat source equals to the shape factor of second heat source with respect to first heat source. The shape factor of one heat source with respect to another heat source can be calculated by using the shape factor algebra such as Hottel's cross string method, enclosure theory, symmetry arguments etc.

The shape factors of heat sources at the different positions with respect to each other is given in Table 5. A small shape factor of one heat source with respect to another heat source causes smaller radiant energy received by one heat source from another heat source and hence the better radiative cooling of the two heat sources is achieved. Comparison between $\overline{\mathrm{Nu}}_{\mathrm{R}}$ at the two heat sources in the different cases underlines the importance of shape factor of one heat source with respect to another heat source explaining its radiative cooling.
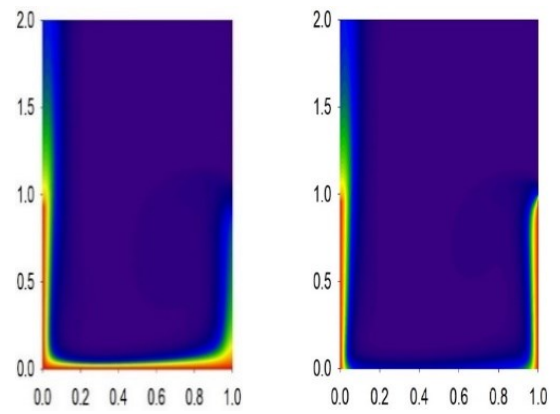

Case II

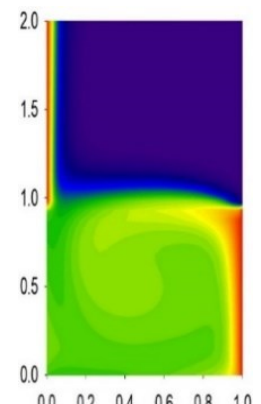

Case III

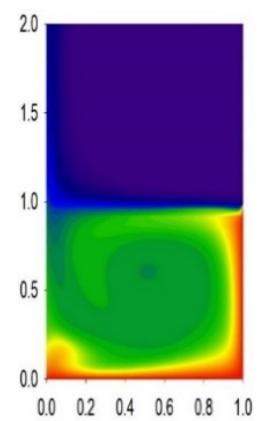

Case V

Case VI

Fig. 6 Isotherm color contours for the six cases $\left(A=2, N_{\mathrm{rc}}=22.6253\right.$, $\mathrm{Pr}=0.70, \mathrm{RaH}=1.075 \times 10^{6}, \mathrm{~T}_{\mathrm{R}}=0.872, \mathrm{~W} 1=\mathrm{W} 2=0.50$, $\varepsilon=0.85)$.

Table 5 Shape factors of one heat source with respect to another heat source in different cases.

\begin{tabular}{|l|l|l|}
\hline \multirow{2}{*}{ Case No. } & \multicolumn{2}{|l|}{$\begin{array}{l}\text { Shape Factor of One heat source with respect to } \\
\text { another heat source }\end{array}$} \\
\cline { 2 - 3 } & Symbol & Value \\
\hline I & $\mathrm{F}_{1,2}=\mathrm{F}_{2,1}$ & 0 \\
\hline II & $\mathrm{F}_{1,3}=\mathrm{F}_{3,1}$ & 0.2929 \\
\hline III & $\mathrm{F}_{1,4}=\mathrm{F}_{4,1}$ & 0.4142 \\
\hline IV & $\mathrm{F}_{2,3}=\mathrm{F}_{3,2}$ & 0.0891 \\
\hline V & $\mathrm{F}_{2,4}=\mathrm{F}_{4,2}$ & 0.2038 \\
\hline VI & $\mathrm{F}_{3,4}=\mathrm{F}_{4,3}$ & 0.2929 \\
\hline
\end{tabular}

\subsection{Comparison between $\overline{\mathrm{Nu}}_{\mathrm{C}}, \overline{\mathrm{Nu}}_{\mathrm{R}}$ and $\overline{\mathrm{Nu}}_{\mathrm{T}}$ at the two isothermal heat sources in the different cases}

The values of $\overline{\mathrm{Nu}}_{\mathrm{C}}, \overline{\mathrm{Nu}}_{\mathrm{R}}$ and $\overline{\mathrm{Nu}}_{\mathrm{T}}$ for $\mathrm{A}=2, \mathrm{~N}_{\mathrm{rc}}=22.6253, \mathrm{Pr}=0.70$, $\mathrm{Ra}_{\mathrm{H}}=1.075 \times 10^{6}, \mathrm{~T}_{\mathrm{R}}=0.872, \mathrm{~W} 1=\mathrm{W} 2=0.50, \varepsilon=0.85$ at the two isothermal heat sources in the different cases is tabulated in Table 6.

At a high value of emissivity $(\varepsilon=0.85)$ in each of the case considered, the value of $\overline{\mathrm{Nu}}_{\mathrm{C}}$ and $\overline{\mathrm{Nu}}_{\mathrm{R}}$ are comparable and hence the heat transfer due to the natural convection and the surface radiation are comparable. Hence, the heat transferred by the surface radiation can't be neglected in comparison with the heat transfer by the natural convection. 
Table 6 Values of $\overline{\mathrm{Nu}}_{\mathrm{C}}, \overline{\mathrm{Nu}}_{\mathrm{R}}$ and $\overline{\mathrm{Nu}}_{\mathrm{T}}$ at the two isothermal heat sources in different cases $\left(\mathrm{A}=2, \mathrm{~N}_{\mathrm{rc}}=22.6253, \mathrm{Pr}=0.70\right.$, $\left.\mathrm{RaH}=1.075 \times 10^{6}, \mathrm{~T}_{\mathrm{R}}=0.872, \mathrm{~W} 1=\mathrm{W} 2=0.50, \varepsilon=0.85\right)$.

\begin{tabular}{|l|l|l|l|l|}
\hline $\begin{array}{l}\text { Case } \\
\text { No. }\end{array}$ & $\begin{array}{l}\text { Location of } \\
\text { Isothermal Walls }\end{array}$ & $\overline{N u}_{C}$ & $\overline{N u}_{R}$ & $\overline{N u}_{T}$ \\
\hline \multirow{4}{*}{ I } & 1 (Left Bottom) & 16.40 & 13.01 & 29.41 \\
\cline { 2 - 5 } & 2 (Left Top) & 10.68 & 14.54 & 25.22 \\
\hline \multirow{2}{*}{ II } & 1 (Left Bottom) & 13.56 & 8.31 & 21.87 \\
\cline { 2 - 5 } & 3 (Bottom) & 12.88 & 8.45 & 21.33 \\
\hline \multirow{2}{*}{ IV } & 1 (Left Bottom) & 16.33 & 8.32 & 24.65 \\
\cline { 2 - 5 } & 4 (Right Bottom) & 16.06 & 7.00 & 23.06 \\
\hline \multirow{3}{*}{ V } & 2 (Left Top) & 14.49 & 12.74 & 27.23 \\
\cline { 2 - 5 } & 3 (Bottom) & 4.87 & 8.78 & 13.65 \\
\hline \multirow{2}{*}{ VI } & 2 (Left Top) & 14.26 & 12.21 & 26.47 \\
\cline { 2 - 5 } & 4 (Right Bottom) & 5.83 & 7.21 & 13.04 \\
\cline { 2 - 5 } & 3 (Bottom) & 5.35 & 8.64 & 13.99 \\
\cline { 2 - 5 } & 4 (Right Bottom) & 5.46 & 7.64 & 13.10 \\
\hline
\end{tabular}

\section{Comparison between $\overline{\mathbf{N u}}_{\mathrm{C}}, \overline{\mathbf{N u}}_{\mathrm{R}}$ and $\overline{\mathrm{Nu}}_{\mathrm{T}}$ in Case I}

In the case I, the two isothermal heat sources are located at the left bottom and the left top of the cavity. There at the left bottom isothermal wall, the values of $\overline{\mathrm{Nu}}_{\mathrm{C}}$ and $\overline{\mathrm{Nu}}_{\mathrm{R}}$ are 16.40 and 13.01 respectively. This indicates that for the left bottom isothermal wall, the heat transfer by natural convection is more than the heat transfer by surface radiation. At the left top isothermal wall, the values of $\overline{\mathrm{Nu}}_{\mathrm{C}}$ and $\overline{\mathrm{Nu}}_{\mathrm{R}}$ are 10.68 and 14.54 respectively. Thus, there the heat transfer by the surface radiation is quite larger than the heat transfer by natural convection.

The heat transfer by natural convection at the left bottom isothermal wall is significantly greater than that at the left top isothermal wall. The heat transfer by surface radiation at the left top isothermal wall is greater than that at the left bottom isothermal wall.

This may be explained by the presence of adjacent top opening and a port in front of the left top isothermal wall. This causes more thermal radiation escaping out from the left top isothermal wall than from the left bottom isothermal wall without irradiated back by the solid adiabatic walls. The streamlines pattern in the cavity shows the ambient air entering from right top port and rising along the left wall. The temperature of air coming in contact to left bottom isothermal wall is close to the ambient temperature, which gains some heat from this wall and then after it interacts with the left top isothermal wall. Thus, the air stream gains more heat from the left bottom isothermal wall than the heat it gains from the left top isothermal wall. The air circulation loop at the right bottom corner may also be noted.

\section{Comparison between $\overline{\mathbf{N u}}_{\mathrm{C}}, \overline{\mathrm{Nu}}_{\mathrm{R}}$ and $\overline{\mathrm{Nu}}_{\mathrm{T}}$ in Case II}

In the case II, the two isothermal heat sources are located at the left bottom and the bottom of the cavity. Here the two isothermal heat sources are adjacent to each other viewing each other. There at the left bottom isothermal wall, the values of $\overline{\mathrm{Nu}}_{\mathrm{C}}$ and $\overline{\mathrm{Nu}}_{\mathrm{R}}$ are 13.56 and 8.31 respectively. There at the bottom isothermal wall, the values of $\overline{\mathrm{Nu}}_{\mathrm{C}}$ and $\overline{\mathrm{Nu}}_{\mathrm{R}}$ are 12.88 and 8.45 respectively. Thus, both the left bottom isothermal wall and the bottom isothermal wall loses more heat by natural convection than by the surface radiation.

It is also observed that the cooling by natural convection at the vertical left bottom isothermal wall is greater than that at the bottom isothermal wall. The cooling by surface radiation of these two isothermal walls are comparable and almost the same.

But the lower value of $\overline{\mathrm{Nu}}_{\mathrm{T}}\left(=\overline{\mathrm{Nu}}_{\mathrm{C}}+\overline{\mathrm{Nu}}_{\mathrm{R}}\right)$ at the two isothermal heat sources indicates the weak cooling of these two isothermal heat sources. The reasons assigned are presence of two isothermal heat sources facing each other and the interaction of the thermal boundary layers of two isothermal heat sources. The air circulation loop at the right bottom corner is present in this case also.

\section{Comparison between $\overline{\mathrm{Nu}}_{\mathrm{C}}, \overline{\mathrm{Nu}}_{\mathrm{R}}$ and $\overline{\mathrm{Nu}}_{\mathrm{T}}$ in Case III}

In the case III, the two isothermal heat sources are located at the left bottom and the right bottom of the cavity. Here the two isothermal heat sources are parallel and facing towards each other. There at the left bottom isothermal wall, the values of $\overline{\mathrm{Nu}}_{\mathrm{C}}$ and $\overline{\mathrm{Nu}}_{\mathrm{R}}$ are 16.33 and 8.32 respectively. There at the right bottom isothermal wall, the values of $\overline{\mathrm{Nu}}_{\mathrm{C}}$ and $\overline{\mathrm{Nu}}_{\mathrm{R}}$ are 16.06 and 7.00 respectively. Thus, for both the heat sources the heat transfer by natural convection is more than the heat transfer by surface radiation.

It is observed that the heat transfer by both the natural convection and the surface radiation is slightly higher at the left bottom isothermal wall than the right bottom isothermal wall.

This may be justified by the presence of a port in the opposite wall of the left bottom heat source and the two parallel vertical heat sources facing towards each other. The air circulation loop at the right bottom corner is present in this case also.

\section{Comparison between $\overline{\mathbf{N u}}_{\mathrm{C}}, \overline{\mathbf{N u}}_{\mathrm{R}}$ and $\overline{\mathbf{N u}}_{\mathrm{T}}$ in Case IV}

In the case IV, the two isothermal heat sources are located at the left top and the bottom of the cavity respectively. There at the left top isothermal wall, the values of $\overline{\mathrm{Nu}}_{\mathrm{C}}$ and $\overline{\mathrm{Nu}}_{\mathrm{R}}$ are 14.49 and 12.74 respectively. There at the bottom isothermal wall, the values of $\overline{\mathrm{Nu}}_{C}$ and $\overline{\mathrm{Nu}}_{\mathrm{R}}$ are 4.87 and 8.78 respectively. In this case, at the left top isothermal wall, the cooling by natural convection is greater than the cooling by surface radiation. But at the bottom isothermal wall, the cooling by natural convection is significantly lower than the cooling by surface radiation.

This also indicates that the cooling of left top isothermal heat source by both of the natural convection and the surface radiation is significantly greater than the cooling of the bottom isothermal heat source.

The reasons attributed for the better cooling of left top isothermal wall by natural convection and surface radiation are the presence of adjacent top opening and a port in front of the left top isothermal wall. This causes more thermal radiation escaping out directly from the left top isothermal wall than that from the bottom isothermal wall without irradiated back by the solid adiabatic walls. The poor cooling of bottom isothermal heat source is supported by the formation of large air circulation loop adjacent to the right bottom adiabatic wall.

\section{Comparison between $\overline{\mathbf{N u}}_{\mathrm{C}}, \overline{\mathbf{N u}}_{\mathrm{R}}$ and $\overline{\mathbf{N u}}_{\mathrm{T}}$ in Case $\mathrm{V}$}

In the case $\mathrm{V}$, the two isothermal heat sources are located at the left top and right bottom of the cavity respectively. There at the left top isothermal wall, the values of $\overline{\mathrm{Nu}}_{\mathrm{C}}$ and $\overline{\mathrm{Nu}}_{\mathrm{R}}$ are 14.26 and 12.21 respectively. There at the right bottom isothermal wall, the values of $\overline{\mathrm{Nu}}_{\mathrm{C}}$ and $\overline{\mathrm{Nu}}_{\mathrm{R}}$ are 5.83 and 7.21 respectively. In this case, the cooling at the left top isothermal wall by natural convection is higher than the cooling by surface radiation. Here at the right bottom isothermal wall the cooling by natural convection is lower than the cooling by surface radiation.

This indicates that the cooling of left top heat source by the natural convection and the surface radiation both is significantly greater than the cooling of the right bottom isothermal heat source.

The better cooling of left top isothermal wall in comparison to the right bottom isothermal wall by both the natural convection and the surface radiation may be attributed to the presence of adjacent top opening and a port in front of the left top isothermal wall. This causes more thermal radiations escaping out directly from the left top isothermal heat source through the top opening and the right top port without irradiated back by the solid adiabatic walls in comparison with the right bottom isothermal heat source. This is well supported by the formation of large air circulation loop adjacent to the right bottom isothermal wall. 


\section{Comparison between $\overline{\mathbf{N u}}_{\mathrm{C}}, \overline{\mathbf{N u}}_{\mathrm{R}}$ and $\overline{\mathbf{N u}}_{\mathrm{T}}$ in Case $\mathrm{VI}$}

In the case VI, the two isothermal heat sources are located at the bottom and the right bottom of the cavity. There at the bottom isothermal wall, the values of $\overline{\mathrm{Nu}}_{\mathrm{C}}$ and $\overline{\mathrm{Nu}}_{\mathrm{R}}$ are 5.35 and 8.64 respectively. There at the right bottom isothermal wall, the values of $\overline{\mathrm{Nu}}_{\mathrm{C}}$ and $\overline{\mathrm{Nu}}_{\mathrm{R}}$ are 5.46 and 7.64 respectively. Here the two heat sources are adjacent to each other viewing each other. The lower values of $\overline{\mathrm{Nu}}_{\mathrm{C}}$ and $\overline{\mathrm{Nu}}_{\mathrm{R}}$ at the bottom isothermal heat source and right bottom isothermal heat source indicates the poor heat transfer by natural convection and surface radiation.

This may be attributed to the presence of the two heat sources adjacent to each other. The formation of large primary air circulation loop at the bottom adjacent to the right bottom isothermal wall with a small secondary air circulation loop at the left bottom corner causes poor cooling of the two heat sources.

\subsection{Remarks}

On the detail analysis of the above results obtained for the different cases, the following observations are made.

1. The cooling of heat source by natural convection and surface radiation is enhanced, when it is placed near an opening like adjacent to the top opening and in front of the right top open port.

2. The cooling by natural convection is higher in the case of a vertical heat source than in the case of a horizontal heat source. In all the cases discussed above the cooling of isothermal heat sources is poor, when it is placed at bottom i.e. horizontally in the position no. 3 .

3 . The cooling of a heat source is adversely affected by the presence of another heat source in the vicinity viewing each other. Larger the shape factor of one heat source with respect to another heat source, weaker is the cooling of the two heat sources.

4. The interaction of the thermal boundary layers of the two heat sources may adversely affect the cooling of the two heat sources.

5. The large air circulation loops in the cavity cause the poor cooling of the heat sources.

6. At some positions of heat sources the cooling by either the natural convection or the surface radiation is higher. At the some other positions of heat sources the cooling by both of the natural convection and the surface radiation is higher than the other positions of the cavity. The overall heat transfer from a heat source can be determined by taking both of the natural convection and the surface radiation into account.

On the basis of the comparison of $\overline{\mathrm{Nu}_{\mathrm{C}}}, \overline{\mathrm{Nu}_{\mathrm{R}}}$ and $\overline{\mathrm{Nu}}_{\mathrm{T}}$ $\left(=\overline{\mathrm{Nu}}_{\mathrm{C}}+\overline{\mathrm{Nu}}_{\mathrm{R}}\right)$ in the different cases, better cooling of heat sources is observed in the cases I \& III. Therefore, only the cases I and III are analyzed further in order to find an optimal placement of the two isothermal heat sources for their optimal cooling. The reasons of the optimal cooling of heat sources achieved in a position is also discussed.

\section{TYPICAL RESULTS OF CASES I AND III}

There are numerous factors affecting the cooling of heat sources within the cavity. Thus, it is difficult to find the explicit conditions for the efficient cooling of heat sources on the basis of a few parameters only. Now these two cases are investigated further to find the air velocity and temperature distribution inside the cavity. The effect of emissivity of the cavity walls on $\overline{\mathrm{Nu}_{\mathrm{C}}}$ and $\overline{\mathrm{Nu}_{\mathrm{R}}}$ is analyzed. The variation of local $\mathrm{Nu}_{\mathrm{C}}$ and local Nur with height is also studied.

\subsection{Variation of temperature inside the cavity}

Figures 7 and 8 show the variation of temperature in the cavity at the three horizontal planes i.e. at the bottom, middle and top horizontal sections of the cavity corresponding to the cases I and III respectively. At the bottom surface, the temperature is significantly higher indicating the radiative interaction of the two heat sources with the bottom adiabatic wall in both of the cases. In these two cases, it is also observed that the temperature at the points away from the bottom surface and side walls is always close to the ambient temperature. This is due to the continuous intake of the fresh ambient air through the top opening and right port while the hot air leaving through the top opening.

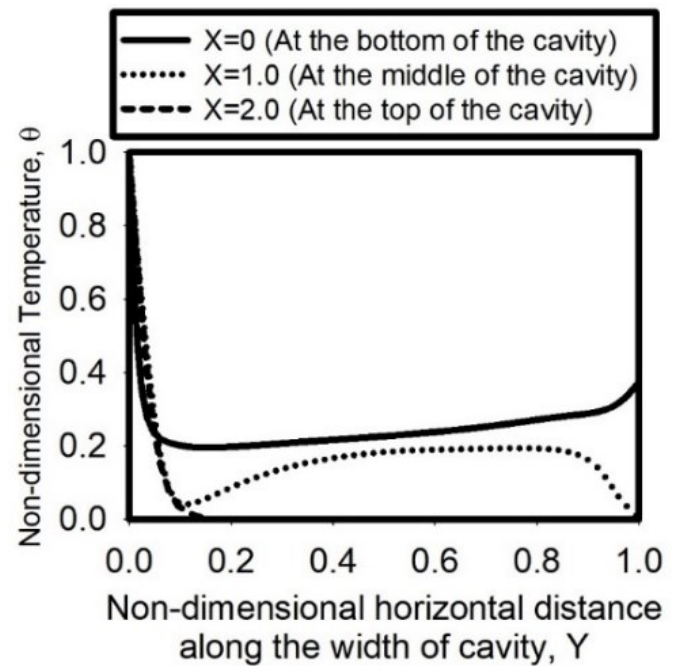

Fig. 7 Temprature variation at different horizontal sections of the cavity for the Case I $\left(\mathrm{A}=2, \mathrm{~N}_{\mathrm{rc}}=22.6253, \mathrm{Pr}=0.70\right.$, $\left.\mathrm{RaH}_{\mathrm{H}}=1.075 \times 10^{6}, \mathrm{~T}_{\mathrm{R}}=0.872, \mathrm{~W} 1=\mathrm{W} 2=0.50, \varepsilon=0.85\right)$.

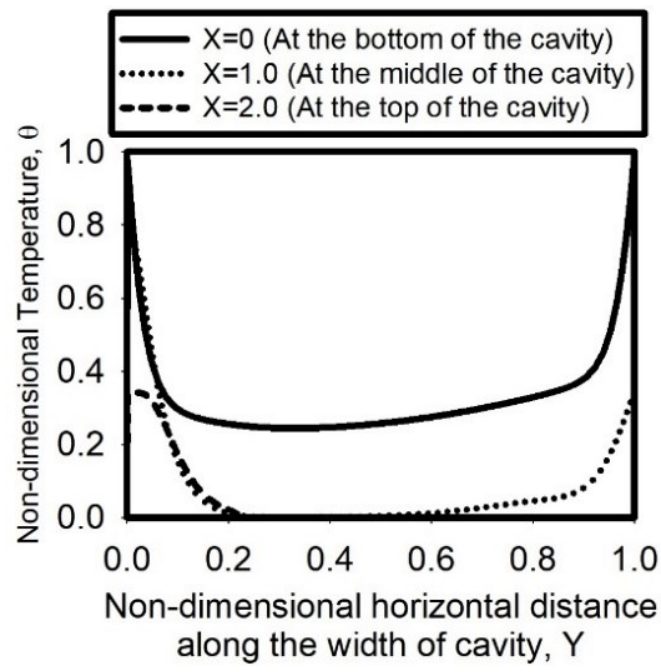

Fig. 8 Temprature variation at different horizontal sections of the cavity for the Case III $\left(\mathrm{A}=2, \mathrm{~N}_{\mathrm{rc}}=22.6253, \operatorname{Pr}=0.70\right.$, $\left.\mathrm{Ra}_{\mathrm{H}}=1.075 \times 10^{6}, \mathrm{~T}_{\mathrm{R}}=0.872, \mathrm{~W} 1=\mathrm{W} 2=0.50, \varepsilon=0.85\right)$.

\subsection{Variation of vertical velocity $U$ inside the cavity}

Figures 9 and 10 show the variation of the non-dimensional vertical velocity at the middle and top horizontal sections of the cavity corresponding to the cases I and III respectively. Here in both the cases, there is a strong upward convective air current near the left and right side walls. The non-dimensional vertical velocity at the top horizontal section near the left wall is higher in the case I than in the case III due to the presence of two isothermal heat sources on the left wall of the cavity in the case I. The non-dimensional vertical velocity at the middle horizontal section near the right bottom wall is higher in the case III than in the case I due to the presence of an isothermal heat source on the right wall in the case III. In both the cases, the non-dimensional vertical velocity near the right wall at the top horizontal section is close to zero due to the presence of open top and large right side opening or port. At the middle of the left and right wall the non-dimensional vertical velocity at the middle horizontal section is negative i.e. in the downward direction. This is due 


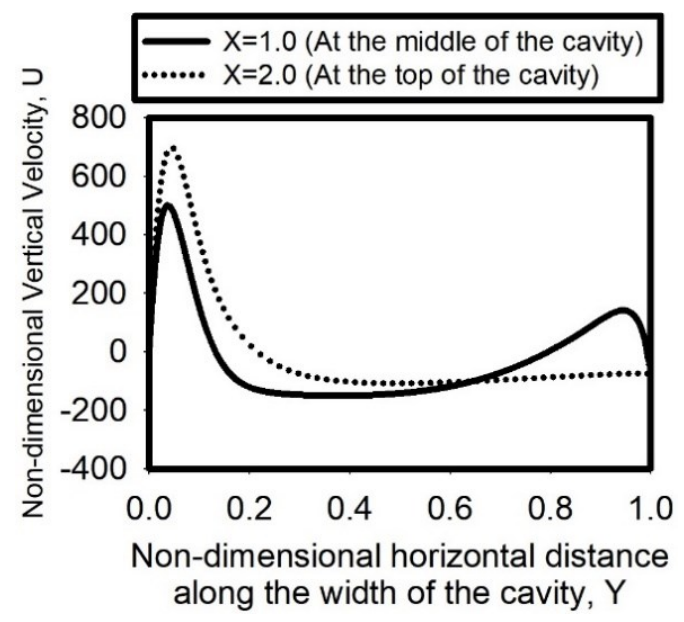

Fig. 9 Variation of non-dimensional vertical velocity $U$ inside the cavity at different sections for Case $\mathrm{I}\left(\mathrm{A}=2, \mathrm{~N}_{\mathrm{rc}}=22.6253\right.$, $\mathrm{Pr}=0.70, \mathrm{RaH}_{\mathrm{H}}=1.075 \times 10^{6}, \mathrm{~T}_{\mathrm{R}}=0.872, \mathrm{~W} 1=\mathrm{W} 2=0.50$, $\varepsilon=0.85)$.

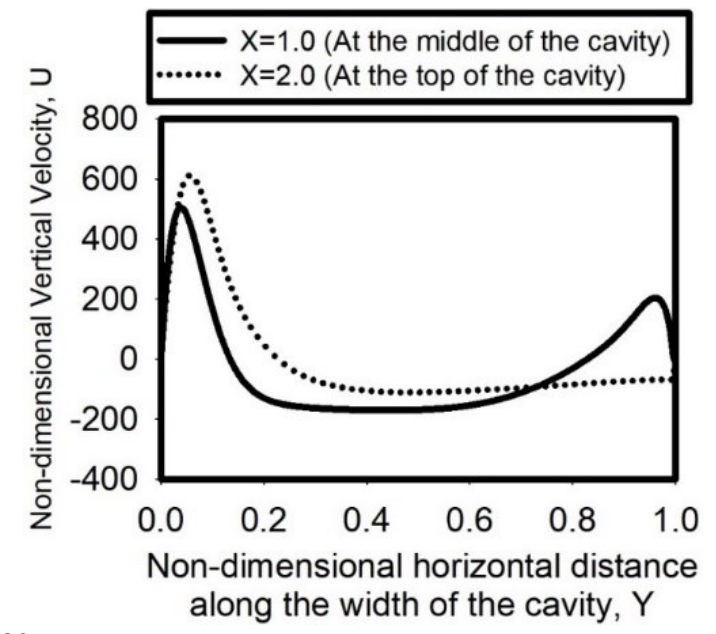

Fig. 10 Variation of non-dimensional vertical velocity $U$ inside the cavity at different sections for Case III $\left(\mathrm{A}=2, \mathrm{~N}_{\mathrm{rc}}=22.6253\right.$, $\operatorname{Pr}=0.70, \mathrm{RaH}=1.075 \times 10^{6}, \mathrm{~T}_{\mathrm{R}}=0.872, \mathrm{~W} 1=\mathrm{W} 2=0.50$, $\varepsilon=0.85)$.

\subsection{Variation of $\overline{\mathrm{Nu}_{\mathrm{C}}}$ and $\overline{\mathrm{Nu}_{\mathrm{R}}}$ with emissivity}

Figures 11 and 12 show the variation of $\overline{\mathrm{Nu}_{\mathrm{C}}}$ and $\overline{\mathrm{Nu}_{\mathrm{R}}}$ at the two heat sources with the emissivity of cavity walls in the cases I and III respectively. Here the emissivity of all the cavity walls is considered to be the same in both of the cases. It is observed that in both of the cases, the value of $\overline{\mathrm{Nu}_{\mathrm{C}}}$ at the two heat sources in the cavity is almost constant with the increase in emissivity of the cavity walls. But in these two cases, the $\overline{\mathrm{Nu}_{\mathrm{R}}}$ at the two heat sources in the cavity increases almost linearly with the increase in emissivity of the cavity walls.

In the case $\mathrm{I}, \overline{\mathrm{Nu}_{\mathrm{C}}}$ at the left bottom heat source varies from 16.70 to 16.33 with the variation in emissivity of cavity walls from 0.05 to 0.95 . In this case, $\overline{\mathrm{Nu}_{\mathrm{C}}}$ at the left top heat source varies from 11.18 to 10.67 with the variation in emissivity of cavity walls from 0.05 to 0.95 .

In the case $\mathrm{I}, \overline{\mathrm{Nu}_{\mathrm{R}}}$ at the left bottom heat source varies from 0.90 to 14.58 , whereas the emissivity of the cavity walls varies from 0.05 to 0.95. In this case, $\overline{\mathrm{Nu}_{\mathrm{R}}}$ at the left top heat source varies from 0.91 to 16.26, whereas the emissivity of the cavity walls varies from 0.05 to 0.95 .

The $\overline{\mathrm{Nu}_{\mathrm{C}}}$ at the left bottom heat source is higher than the $\overline{\mathrm{Nu}_{\mathrm{C}}}$ at the left top heat source. The higher value of $\overline{\mathrm{Nu}_{\mathrm{C}}}$ at the left bottom heat source than $\overline{\mathrm{Nu}_{\mathrm{C}}}$ at the left top heat source may be attributed to its interaction with the incoming fresh air stream at the ambient temperature.
The temperature of the ambient air rises by gaining some heat from the left bottom isothermal wall before interacting with the left top isothermal wall.

The $\overline{\mathrm{Nu}_{\mathrm{R}}}$ at the left top heat source is higher than the $\overline{\mathrm{Nu}_{\mathrm{R}}}$ at the left bottom heat source. The higher value of $\overline{\mathrm{Nu}_{\mathrm{R}}}$ at the left top heat source than the $\overline{\mathrm{Nu}_{\mathrm{R}}}$ at the left bottom heat source may be attributed to the presence of adjacent top opening and a port in front of the left top isothermal wall. This causes more thermal radiations escaping out directly from the left top isothermal wall through the top opening and right top port. But a large fraction of the thermal radiations from the left bottom isothermal wall is irradiated back by the right adiabatic walls in front of it.

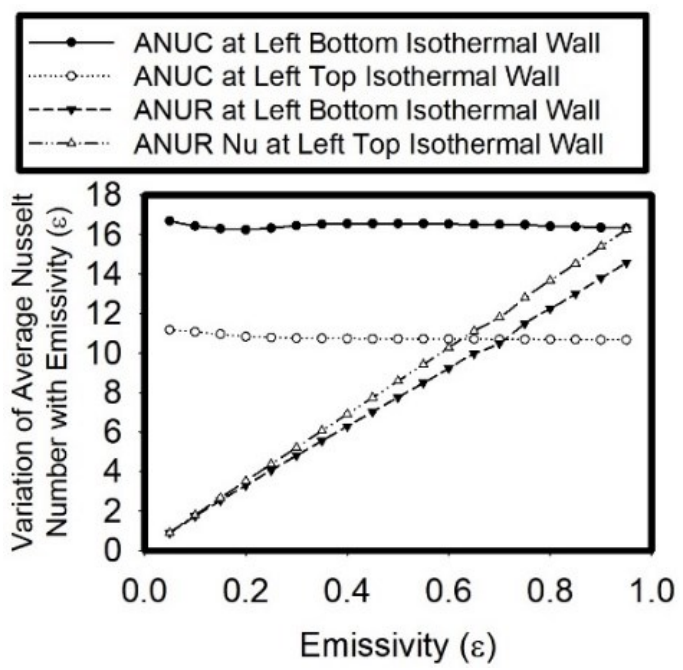

Fig. 11 Variation of $\overline{\mathrm{Nu}_{\mathrm{C}}}$ (ANUC) and $\overline{\mathrm{Nu}_{\mathrm{R}}}$ (ANUR) with emissivity of cavity wall for Case I $\left(\mathrm{A}=2, \mathrm{~N}_{\mathrm{rc}}=22.6253\right.$, $\left.\mathrm{Pr}=0.70, \mathrm{Ra}_{\mathrm{H}}=1.075 \times 10^{6}, \mathrm{~T}_{\mathrm{R}}=0.872, \mathrm{~W} 1=\mathrm{W} 2=0.50\right)$.

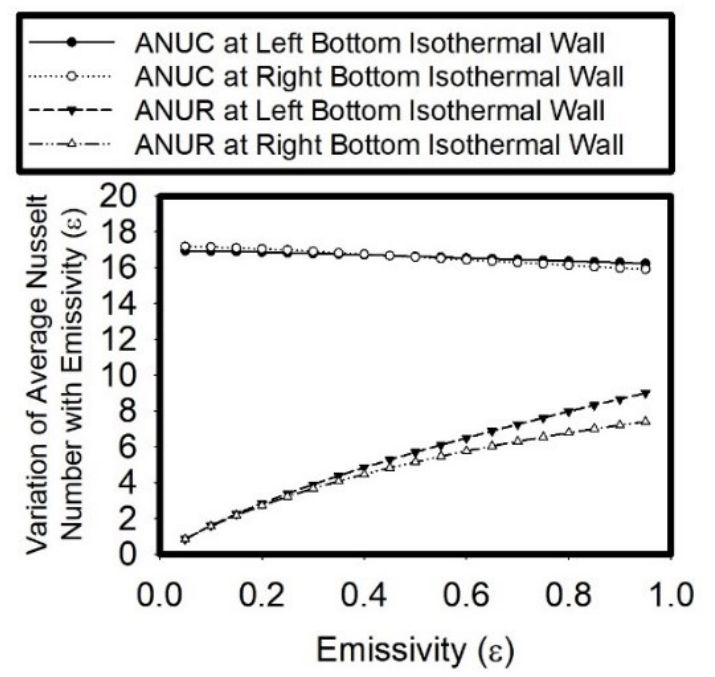

Fig. 12 Variation of $\overline{\mathrm{Nu}_{\mathrm{C}}}$ (ANUC) and $\overline{\mathrm{Nu}_{\mathrm{R}}}$ (ANUR) with emissivity of cavity wall for Case III $\left(\mathrm{A}=2, \mathrm{~N}_{\mathrm{rc}}=22.6253\right.$, $\left.\operatorname{Pr}=0.70, \mathrm{Ra}_{\mathrm{H}}=1.075 \times 10^{6}, \mathrm{~T}_{\mathrm{R}}=0.872, \mathrm{~W} 1=\mathrm{W} 2=0.50\right)$.

In the case III, $\overline{\mathrm{Nu}_{\mathrm{C}}}$ at the left bottom heat source varies from 16.95 to 16.24 with the variation in emissivity of cavity walls from 0.05 to 0.95 . In this case, $\overline{\mathrm{Nu}_{\mathrm{C}}}$ at the right bottom heat source varies from 17.19 to 15.93 with the variation in emissivity of cavity walls from 0.05 to 0.95 .

In the case III, $\overline{\mathrm{Nu}_{\mathrm{R}}}$ at the left bottom heat source varies from 0.85 to 9.01 , whereas emissivity of the cavity walls varies from 0.05 to 0.95 . In this case, $\overline{\mathrm{Nu}_{\mathrm{R}}}$ at the right bottom heat source varies from 0.84 to 7.40 , whereas emissivity of the cavity walls varies from 0.05 to 0.95 . 
The $\overline{\mathrm{Nu}_{\mathrm{C}}}$ at the left bottom isothermal wall and right bottom isothermal wall at the different emissivity of the cavity walls are almost the same due to their similar positions in the cavity.

The $\overline{\mathrm{Nu}_{\mathrm{R}}}$ at the left bottom isothermal wall is higher in comparison with the $\overline{\mathrm{Nu}_{\mathrm{R}}}$ at the right bottom isothermal wall at the different emissivity of the cavity walls. This may be attributed to the presence of the right port in the opposite wall of the left bottom isothermal wall.

\subsection{Variation of local $\mathrm{Nu}$ and local $\mathrm{Nu}_{\mathrm{R}}$ with height}

Figures 13 and 14 show the variation of local $\mathrm{Nu}_{\mathrm{C}}$ and local $\mathrm{Nu}_{\mathrm{R}}$ with height (X) for the cases I and III respectively.

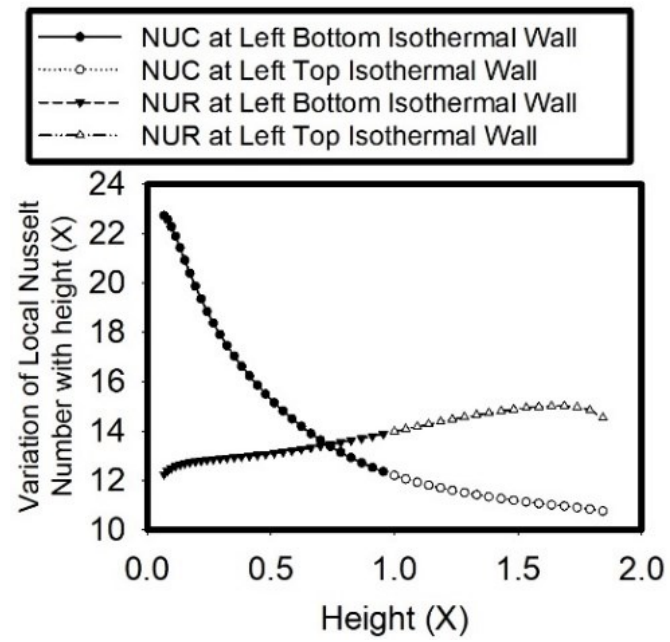

Fig. 13 Variation of local $\mathrm{Nuc}(\mathrm{NUC})$ and local $\mathrm{NuR}$ (NUR) with height $(\mathrm{X})$ for Case $\mathrm{I}\left(\mathrm{A}=2, \mathrm{~N}_{\mathrm{rc}}=22.6253, \mathrm{Pr}=0.70\right.$, $\left.\mathrm{Ra}_{\mathrm{H}}=1.075 \times 10^{6}, \mathrm{~T}_{\mathrm{R}}=0.872, \mathrm{~W} 1=\mathrm{W} 2=0.50, \varepsilon=0.85\right)$.

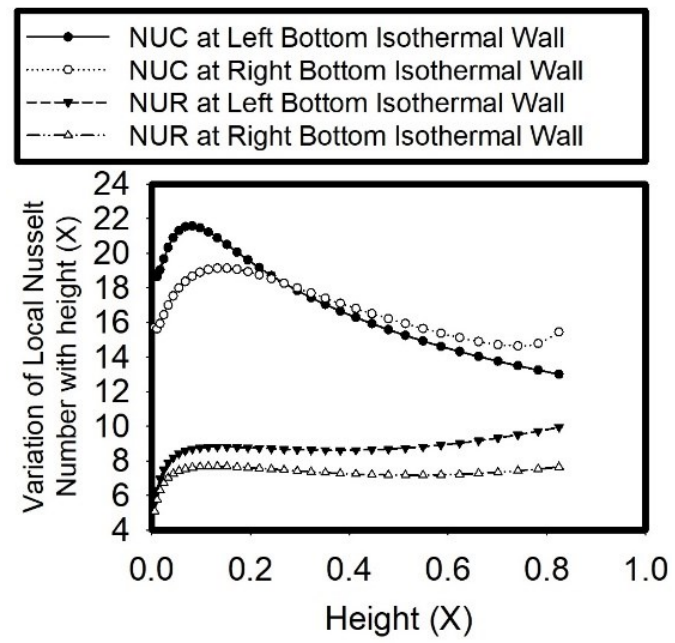

Fig. 14 Variation of local $\mathrm{Nu}_{\mathrm{C}}$ (NUC) and local $\mathrm{Nu}_{\mathrm{R}}$ (NUR) with height $(\mathrm{X})$ for Case III $\left(\mathrm{A}=2, \mathrm{~N}_{\mathrm{rc}}=22.6253, \mathrm{Pr}=0.70\right.$, $\left.\mathrm{Ra}_{\mathrm{H}}=1.075 \times 10^{6}, \mathrm{~T}_{\mathrm{R}}=0.872, \mathrm{~W} 1=\mathrm{W} 2=0.50, \varepsilon=0.85\right)$.

Here in both of the cases, the local Nuc at the hot isothermal walls decreases with height. However, the gradient is steeper in the case I than in the case III. The incoming fresh ambient air enters in the cavity through the right top port, reaches to the hot bottom surface and rises along the vertical isothermal heat sources. In this process, it gradually gains some heat from the hot bottom wall and vertical isothermal heat sources and becomes hotter. Thus, the non-dimensional temperature gradient in the horizontal direction perpendicular to the heat sources decreases with height. This is indicated by the decreased local $\mathrm{Nu}_{\mathrm{C}}$ at the hot isothermal walls with height.
In both of these cases, the local $\mathrm{Nu}_{\mathrm{R}}$ at the isothermal walls increases slightly with height. With the increase in height at the points closer to the top open end and open right top port, the irradiation received from other walls decreases resulting in slight increase in the local $\mathrm{Nu}_{\mathrm{R}}$.

\subsection{General Discussion}

From the above results, it is observed that at the lower emissivity of cavity walls, the natural convection is dominant mode of heat transfer. With the increase in emissivity the heat transfer by thermal radiation increases and at the higher emissivity of cavity walls the heat transfer by natural convection and surface radiation becomes comparable. At the higher emissivity of cavity walls, the heated walls or heat sources loses heat to other adiabatic walls through the thermal radiation, which in turn loses heat to the incoming ambient air. The presence of thermal boundary layers at all the adiabatic walls can be observed as a strong evidence of radiative interaction between the isothermal walls and the adiabatic walls.

Cooling by natural convection and surface radiation is enhanced by the presence of the opening or port near the heat sources. Cooling by natural convection is strongly dependent on the orientation of the heat sources and it is significantly better in the case of a vertical heat source than in the case of a horizontal heat source.

Cooling by surface radiation is significantly better in the case, when the heat sources are opposite to the port or near the openings. Cooling of a heat source is affected by the presence of another heat source in near vicinity viewing each other. A small shape factor of one heat source with respect to another heat source causes smaller radiant energy received by a heat source from another heat source and hence the better radiative cooling of the two heat sources is achieved. Larger the shape factor of one heat source with respect to another heat source, weaker is the cooling of the two heat sources. The interaction of boundary layers of two heat sources may adversely affect the cooling of two heat sources. The shape factor of one heat source with respect to another heat source is minimum i.e. zero in the case I and hence the best radiative cooling is achieved in this case.

The air circulation loops cause the poor cooling of the heat sources. The air circulation loops must be avoided to achieve efficient cooling of heat sources by the natural convection. There some minor air circulation loops are present at the corners causing the poor convective cooling of heat sources at the corners. The formation of these minor air circulation loops must be avoided in order to improve the cooling of heat sources near the corners.

At some positions of the heat sources the cooling by natural convection is higher, whereas at the some other positions of the heat sources the cooling by surface radiation is higher. At some positions, the cooling of heat sources by both of the natural convection and the surface radiation is higher than the other positions of the cavity. The overall heat transfer from a heat source can be determined by taking both of the natural convection and the surface radiation into account.

In the present geometry, the heat sources have the maximum cooling by the natural convection in the case III. The maximum cooling of heat sources by the surface radiation is observed in the case I. But the overall maximum cooling i.e. optimal cooling by the natural convection and surface radiation combined is observed in the case I.

\section{CONCLUSIONS}

On the basis of present study and discussion, the following conclusions can be made.

1. The heated walls or heat sources loses heat to other adiabatic walls through the thermal radiation, which in turn loses heat to incoming ambient air by natural convection.

2. Cooling of heat sources by natural convection and surface radiation is enhanced by the presence of the openings or ports near the heat sources.

3. Cooling of heat sources by natural convection is strongly dependent on the orientation of heat sources. 
4. The air circulation loops cause the poor cooling of the heat sources.

5. Cooling of a heat source by natural convection and surface radiation is affected by the presence of another heat source in near vicinity viewing each other.

6. A small shape factor of one heat source with respect to another heat source causes smaller radiant energy received by one heat source from another heat source and hence the better radiative cooling of the two heat sources is achieved.

7. At the higher emissivity of cavity walls, the heat transfer by natural convection and surface radiation becomes comparable.

8 . The overall heat transfer from a heat source must be determined by taking both the natural convection and surface radiation into account

9. In the present problem, the maximum cooling of heat sources by natural convection is observed in the case III, whereas the maximum cooling of heat sources by the surface radiation is observed in the case I.

10. The overall maximum cooling i.e. the optimum cooling of heat sources by the natural convection and the surface radiation combined is observed in the case I.

\section{NOMENCLATURE}

A aspect ratio $=\mathrm{H} / \mathrm{d}$

$d \quad$ spacing between the left and right walls (m)

$F_{i, j} \quad$ view factor or shape factor between the elements $\mathrm{i}$ and $\mathrm{j}$

$g \quad$ acceleration due to gravity $\left(9.81 \mathrm{~m} . \mathrm{s}^{-2}\right)$

$G \quad$ dimensionless elemental irradiation

$G r_{H} \quad$ Grashof Number (based on $\mathrm{H}$ ) $=\mathrm{g} \beta\left(\mathrm{T}_{\mathrm{h}}-\mathrm{T}_{\infty}\right) \mathrm{H}^{3} / \mathrm{v}^{2}$

$H \quad$ height of the cavity (m)

$J \quad$ dimensionless elemental radiosity

$k \quad$ thermal conductivity of dry air $(\mathrm{W} / \mathrm{m}-\mathrm{K})$

$m$ total number of grid points in horizontal $\mathrm{Y}$ direction

$n \quad$ total number of grid points in vertical $\mathrm{X}$ direction

$N_{r c} \quad$ radiation-conduction parameter $=\sigma \mathrm{T}_{\mathrm{h}}{ }^{4} /\left[\mathrm{k}\left(\mathrm{T}_{\mathrm{h}}-\mathrm{T}_{\infty}\right) / \mathrm{d}\right]$

$\mathrm{Nu} \quad$ convection Nusselt number

$\overline{N u_{C}} \quad$ average convection Nusselt number

$N u_{R} \quad$ radiation Nusselt number

$\overline{N u_{R}} \quad$ average radiation Nusselt number

$\overline{N u_{T}}$

$\operatorname{Pr}$

$R a_{H}$

$T$

$T_{h}$

$T_{R}$

$T_{\infty}$

$\Delta T$

$U$

$V$

$w 1$

$w 2$

$W 1$

$W 2$

X

Y

\section{Greek Symbols}

$\alpha \quad$ thermal diffusivity of fluid $\left(\mathrm{m}^{2} \cdot \mathrm{s}^{-1}\right)$

$\beta \quad$ isobaric co-efficient of volumetric thermal expansion of fluid $\left(\mathrm{K}^{-1}\right)$

$\delta \quad$ convergence parameter in percentage

$=\left|\left(\zeta_{\text {new }}-\zeta_{\text {old }}\right) / \zeta_{\text {new }}\right| \times 100$

$\begin{array}{ll}\varepsilon & \text { emissivity of the walls } \\ \zeta & \text { symbol for the any dependent variable }(\psi, \omega, \theta, \mathrm{J}, \mathrm{G}) \text { over }\end{array}$

which convergence test is being applied

$\theta \quad$ dimensionless temperature $=\left(\mathrm{T}-\mathrm{T}_{\infty}\right) /\left(\mathrm{T}_{\mathrm{h}}-\mathrm{T}_{\infty}\right)$ $v \quad$ kinematic viscosity of the fluid $\left(\mathrm{m}^{2} . \mathrm{s}^{-1}\right)$

$\sigma \quad$ Stefan Boltzmann constant $\left(5.67 \times 10^{-8} \mathrm{~W} \cdot \mathrm{m}^{-2} \cdot \mathrm{K}^{-4}\right)$

$\psi \quad$ dimensionless stream function

$\omega$ dimensionless vorticity

Subscripts

c convection

$h \quad$ hot

$H \quad$ based on the height $\mathrm{H}$ of the left wall of the side vented open cavity

$i \quad$ any arbitrary elemental area of an enclosure in horizontal direction

any arbitrary elemental area of an enclosure in vertical direction

new present value of any dependent variable $(\psi, \omega, \theta, \mathrm{J}, \mathrm{G})$ obtained in two successive iteration

old previous value of any dependent variable $(\psi, \omega, \theta, \mathrm{J}, \mathrm{G})$ obtained in two successive iteration radiation-conduction

$\begin{array}{ll}r c & \text { radiation } \\ R & \text { radiation }\end{array}$

$T \quad$ total

$\infty \quad$ ambient

\section{REFERENCES}

Abib, A.H., and Jaluria, Y., 1988, "Numerical simulation of the buoyancy-induced flow in a partially open enclosure," Numerical Heat Transfer, 14(2), 235-254. http://dx.doi.org/10.1080/10407788808913642

Alexandersen, Joe, Sigmund, Ole, and Aage, Niels, 2016, "Large scale three-dimensional topology optimisation of heat sinks cooled by natural convection," International Journal of Heat and Mass Transfer, 100, 876891.

http://dx.doi.org/10.1016/i.ijheatmasstransfer.2016.05.013

Angirasa, D., and Mahajan, R.L., 1993, "Natural convection from Lshaped corners with adiabatic and cold isothermal horizontal walls," ASME Journal of Heat Transfer, 115, 149-157.

http://dx.doi.org/10.1115/1.2910641

Balaji, C., and Venkateshan, S.P., 1994, "Interaction of radiation with free convection in an open cavity," International Journal of Heat and Fluid Flow, 15(4), 317-324.

http://dx.doi.org/10.1016/0142-727X(94)90017-5

Balaji, C., and Venkateshan, S.P., 1995, "Combined conduction, convection and radiation in a slot," International Journal of Heat and Fluid Flow, 16(2), 139-144.

http://dx.doi.org/10.1016/0142-727X(94)00014-4

Baudoin, Antoine, Saury, Didier, and Boström, Cecilia, 2017, "Optimized distribution of a large number of power electronics components cooled by conjugate turbulent natural convection," Applied Thermal Engineering, 124, 975-985.

http://dx.doi.org/10.1016/j.applthermaleng.2017.06.058

Cahlon, B., Gertsbakh, I., Schochetman, I.E., and Shillor, M., 1991, “A model for the convective cooling of electronic components with application to optimal placement," Mathematical and Computer Modelling, 15(2), 59-75.

http://dx.doi.org/10.1016/0895-7177(91)90116-O

Cheng, Y.P., Lee, T.S., and Low, H.T., 2008, "Numerical simulation of conjugate heat transfer in electronic cooling and analysis based on field synergy principle," Applied Thermal Engineering, 28(14-15), 18261833.

http://dx.doi.org/10.1016/j.applthermaleng.2007.11.008 
Cuce, Pinar Mert, and Cuce, Erdem, 2014, "Optimization of configurations to enhance heat transfer from a longitudinal fin exposed to natural convection and radiation," International Journal of LowCarbon Technologies, 9(4), 305-310.

http://dx.doi.org/10.1093/ijlct/ctt005

Felczak, M., Więcek, B., and Mey, G. De, 2009, "Optimal placement of electronic devices in forced convective cooling conditions," Microelectronics Reliability, 49(12), 1537-1545.

http://dx.doi.org/10.1016/j.microrel.2009.06.007

Gong, Liang, Zhao, Jin, and Huang, Shanbo, 2015, "Numerical study on layout of micro-channel heat sink for thermal management of electronic devices," Applied Thermal Engineering, 88, 480-490.

http://dx.doi.org/10.1016/j.applthermaleng.2014.09.048

Hati, Mourad, Raji, Abdelghani, Hasnaoui, Mohammed, Naïmi, Mohamed, and Abdallaoui, Mohamed El, 2017, "Optimal Natural Convection Heat Transfer Improvement by Combining Periodic Heating Temperature, Cavity Inclination, and Nanofluid," Heat Transfer Engineering, 38(10), 931-947.

http://dx.doi.org/10.1080/01457632.2016.1212574

Hotta, Tapano Kumar, and Venkateshan, Shakkottai P., 2015, "Optimal Distribution of Discrete Heat Sources Under Natural Convection Using ANN-GA Based Technique," Heat Transfer Engineering, 36(2), 200211.

http://dx.doi.org/10.1080/01457632.2014.909222

Joo, Younghwan, Lee, Ikjin, and Kim, Sung Jin, 2017, "Topology optimization of heat sinks in natural convection considering the effect of shape-dependent heat transfer coefficient," International Journal of Heat and Mass Transfer, 109, 123-133.

http://dx.doi.org/10.1016/j.ijheatmasstransfer.2017.01.099

Karatas, Hakan, and Derbentli, Taner, 2018, "Natural convection and radiation in rectangular cavities with one active vertical wall," International Journal of Thermal Sciences, 123, 129-139.

http://dx.doi.org/10.1016/j.ijthermalsci.2017.09.006

Kwon, Hyeokmin, Joo, Younghwan, and Kim, Sung Jin, 2018, “Analytic approach to thermal optimization of horizontally oriented radial plate-fin heat sinks in natural convection," Energy Conversion and Management, 156, 555-567.

http://dx.doi.org/10.1016/j.enconman.2017.11.076

Lampio, Kaj, and Karvinen, Reijo, 2017, “Optimization of convectively cooled heat sinks," Microelectronics Reliability, 79, 473-479.

http://dx.doi.org/10.1016/j.microrel.2017.06.011

Liu, G.R., Zhou, J.J., and Wang, J.G., 2002, "Coefficients identification in electronic system cooling simulation through genetic algorithm," Computers \& Structures, 80(1), 23-30. http://dx.doi.org/10.1016/S0045-7949(01)00163-8
Lugarini, Alan, Franco, Admilson T., Junqueira, Silvio L.M., and Lage, José L., 2018, "Natural Convection and Surface Radiation in a Heated Wall, C-Shaped Fracture," Journal of Heat Transfer, 140(8), 082501. http://dx.doi.org/10.1115/1.4039643

Ramesh, N., and Merzkirch, W., 2001, "Combined convective and radiative heat transfer in side vented open cavities," International Journal of Heat and Fluid Flow, 22, 180-187. http://dx.doi.org/10.1016/S0142-727X(00)00080-1

Rao, C. Gururaja, Balaji, C., and Venkateshan, S.P., 2000, "Conjugate mixed convection with surface radiation from a vertical plate with discrete heat source," Journal of Heat Transfer, 123(4), 698-702. http://dx.doi.org/10.1115/1.1373654

Rao, C. Gururaja, Balaji, C., and Venkateshan, S.P., 2002, "Effect of surface radiation on conjugate mixed convection in a vertical channel with a discrete heat source in each wall," International Journal of Heat and Mass Transfer, 45(16), 3331-3347.

http://dx.doi.org/10.1016/S0017-9310(02)00061-3

Saglietti, Clio, Schlatter, Philipp, Monokrousos, Antonios, and Henningson, Dan S., 2017, “Adjoint optimization of natural convection problems: differentially heated cavity," Theoretical and Computational Fluid Dynamics, 31(5-6), 537-553. http://dx.doi.org/10.1007/s00162-016-0398-5

Singh, D. K. and Singh, S.N., 2015, "Conjugate free convection with surface radiation in open top cavity," International Journal of Heat and Mass Transfer, 89, 444-453.

http://dx.doi.org/ 10.1016/j.ijheatmasstransfer.2015.05.038

Singh, S.N., and Venkateshan, S.P., 2004, "Numerical study of natural convection with surface radiation in side-vented open cavities," International Journal of Thermal Sciences, 43(9), 865-876. http://dx.doi.org/10.1016/j.ijthermalsci.2004.01.002

Sudhakar, T.V.V., Balaji, C., and Venkateshan, S.P., 2010, “A heuristic approach to optimal arrangement of multiple heat sources under conjugate natural convection," International Journal of Heat and Mass Transfer, 52(1-3), 431-444.

http://dx.doi.org/10.1016/j.ijheatmasstransfer.2009.09.013

Tigner, Julaunica, Sedeh, Mahmoud Moeini, Sharpe, Trena, Bufford, Alexandria and Floyd-Smith, Tamara, 2013, "Analysis of a platform for thermal management studies of microelectronics cooling methods," Applied Thermal Engineering, 60(1-2), 88-95.

http://dx.doi.org/10.1016/j.applthermaleng.2013.06.042

Tseng, Yung-Shin, Fu, Hwai-Hui, Hung, Tzu-Chen and Pei, Bau-Shei, 2007, "An optimal parametric design to improve chip cooling," Applied Thermal Engineering, 27(11-12), 1823-1831.

http://dx.doi.org/10.1016/j.applthermaleng.2007.01.012 